\title{
LIFELONG LEARNING PROGRAMMES FOR SENIORS AT THE OPEN CARE CENTRES FOR THE ELDERLY (KAPI) IN SYROS, GREECE: PREDISPOSITION, EXPECTATIONS, MOTIVATION, LEARNING ENVIRONMENT. THE DECISIVE ROLE OF CULTURE
}

\author{
Christianna Papitsi ${ }^{i}$, \\ Theodore Ganetsos, \\ Dimitris Tseles, \\ Mixail Papoutsidakis, \\ Christos Drosos \\ University of West Attica, \\ Athens, Greece
}

\begin{abstract}
:
The main goal of this survey is to explore lifelong learning in the third age in the island community of Syros in the hope that the findings will provide data that may be useful in creating educational programme structures. Lifelong learning taking place with a group of senior citizens at the KAPI ii in the Municipality of Syros-Ermoupoli will be explored, along with the potential of implementing comprehensive active learning programmes specific to the third age. The topics examined include the idiosyncrasy of the KAPI members, their needs for active ageing, their expectations and motivations, the objects of knowledge they seek and the limitations they set. The principal findings showed that Syros is a fertile field for creating pilot structures for informal education in the third age. The members of the Syros KAPI hope to see such programmes launch with less reticence than expected, but on condition that the present hierarchy of family and social priorities is not radically upset. The elderly are open to the idea of participating in learning programmes, they select specific objects of knowledge and desire to channel the skills they acquire to the local community, which is open to volunteerism. It is noteworthy that in relation to the open-ended questions regarding learning objects, the KAPI members took the initiative to propose cultural education programmes as part of their training. They also believe that the non-formal learning will improve their social image and health and will allow them to become more functional members of the local community.
\end{abstract}

Keywords: lifelong learning, third age, active learning techniques, Syros, culture

\footnotetext{
i Correspondence: email christianna@papitsi.gr

ii Open Care Centres for the Elderly
} 


\section{Introduction}

In Greece, educational programme structures for the third-age population are not as widespread as they are in the EU and globally. The international academic community has fully studied the necessity and benefits of lifelong learning in programmes specially designed for older persons; however, they have not been applied to the fullest extent. Of course, European programmes have been implemented along with related actions on the initiative of non-profit organisations ${ }^{\mathrm{iii}}$, but not adequately and not regularly enough to constitute a new institution.

Older persons need to feel that they are active citizens, to stop feeling lonely and marginalised; meanwhile, remaining inactive within society intensifies their health problems. Nevertheless, the provision of educational structures has limitations that are due to the resistance of the older persons themselves to participate in learning programmes which results from hesitancy and firmly rooted beliefs. Inadequate awareness in Greece of the benefits of active ageing does not help such programmes to succeed.

Moreover, the process of learning in the third age has its own idiosyncrasies in regard to the objects as well as the manner in which information is assimilated by learners. Therefore, even active learning techniques must be adapted to these idiosyncrasies, while the instructor should be experienced in managing the older population and be respectful of the physical and intellectual functions and the mental and emotional changes these age groups undergo.

The interesting aspect of this survey lies in the fact that it is the first time a study is being conducted in relation to the educational programmes for the third age in the geographical space of Syros, a Greek provincial, insular environment where it was found that this field is in a very preliminary stage. Though it was somewhat sad to find it so, it nevertheless gives rise to the optimistic hope that with strong, thorough exploration of needs and proper planning, the appropriate structures could be created and serve as a model that would be useful in creating similar structures in other areas of Greece. In addition, the sample in the study contains data that emphasise the specific characteristics that may relate to the insularity in combination with the history of Syros, as the people now in the third age are mainly individuals who have experienced intense periods of economic adversity that influenced their educational level.

Starting with this question, the factors that influence the decision of older persons to take part in informal education programmes are explored, along with their motivations and expectations, in connection to the intellectual and cultural context of Syros' insular society. Therefore, it is an initial investigation of needs in the specific population segment, relative to the objects of knowledge they would like to engage with and the preconditions they set, given that the study is conducted in a population structure with an established

iii (50plus Hellas (website), n.d.; Hellenic Adult Education Association, n.d.) 
form of collectivity. It was also found that it can contribute to improving the quality of life of third-age people, rendering them active members of a constantly evolving society. This paper is part of a broader research project, the data of which are available. In the conclusion, proposals are put forward so that lifelong learning through educational programmes for the third age can be created and, more importantly, become established in Syros. To that end, a base is created for the practical implementation of a pilot plan in Syros, and by extension in the Cyclades and the rest of the Greek islands, as all as the basis for further research.

\section{Literature review}

\subsection{Lifelong learning and the third age: idiosyncrasies and value}

According to Rogers (1999), a distinction should be made between adult education and education at a mature age. The differentiations are based on two areas: on the one hand, on the objects and content of the programmes, which are better assimilated by older persons, as they relate to their age and the skills they wish to acquire; on the other, on the learning approach that will be adopted given that the programmes are directed at experienced and mature persons.

It is important for third-age classes to work in groups and with their peers so they can exchange experiences. Self-management skills can be improved through peer-to-peer support and ongoing programmes. Older persons tend to be dedicated students who do not attach weight to assessments. However, to respond to the learning challenge, they need to be motivated, to recognise the opportunities being given to them and for there to be a supportive environment. Moreover, the material and technical infrastructure needs to be appropriate to the idiosyncrasies of the third age, such as impaired vision or hearing. Mainly, the objects of the courses should be relevant to the lives of older persons and the acquired knowledge should have short-term and not long-term usefulness. . $^{\text {iv }}$

Informal education is an institution whose natural evolution is to grow. In future, a growing number of older persons will have a higher educational and social background, be in better health and more involved in their education; this will drive better quality programmes.v According to the World Health Organization ${ }^{\text {vi }}$, by 2050, the number of people age 60 or older will have doubled.

It is important to stress that through lifelong learning, people acquire skills that are developed throughout their life, and this process does not only contribute to their personal well-being, but, in the long term, to society as a whole and to local sustainable development. It has been shown that, aside from key socio-political skills, lifelong learning promotes a stronger political conscience and expression in older persons. The programmes that contain learning through cultural commitment show that socio-

\footnotetext{
iv WHO, 2015

v Peterson, 1990

vi "Healthy Ageing and the Sustainable Development Goals", n.d.
} 
political skills combined with the stimulus of cultural interest has more advanced outcomes (Varbanova, 2011).

For older persons, lifelong learning functions as a comfort-provider to help them deal with age-related changes in their lives, such as retirement, the loss of a family member or member of their social network and the decline in skills due to age (The BeLL Project, 2014). According to the World Health Organization report, when older persons continue to pursue experience and skill-related educational processes, they create the following advantages for themselves and for society as a whole (WHO, 2015):

- they develop heightened self-confidence and self-actualisation;

- they retain their participation in community activities;

- there are less dependent on their families and government social services;

- their health and well-being are enhanced;

- they combat stereotypes related to ageism;

- levels of trust between generations are enhanced, creating a sense of common identity where every individual has talents that are used well.

In this context, it is acceptable that older persons could be a target group for cultural organisations like museums for educational activities. It is also a challenge for these acquired skills to evolve into social inclusion activities that demonstrate their contribution to local development, while the individuals remain healthy and active. For example, third-age persons, once trained, can offer their newly acquired skills as dedicated volunteers to serve the goals of the cultural organisation (Hansen \& Zipsane, 2013).

\subsection{Barriers to learning for the third age}

The third age in the second decade of the $21^{\text {st }}$ century comprises the youth of the 1940s, '50s and '60s, which were historically tough times for people's lives and bred insecurity and suspicion. Therefore, it is a natural reaction not to easily trust the workings of a group and to develop dysfunctional behaviours. Manifestations of such behaviours are fear of exposure and insecurity, whilst it is difficult to accept any other learning technique other than traditional teaching. Moreover, they often feel anxious that they will have no control over who participates in each group. This prevents groups from moving into productive stages, where criticism and commitment are important. ${ }^{\text {vii }}$ Barriers may also arise from the emotional investment that adults easily make in knowledge, so that reactions emerge when such knowledge is challenged. In addition, bias can prevent the flow of new knowledge, as well as habit and thinking along acquired patterns. All of the above are self-defence mechanisms that apply to adult learners in general and which become entrenched with advancing age. viii

Besides, since programmes are created specifically for older persons with difficulty participating in lifelong learning programmes, it is clear that the inherent

\footnotetext{
vii Tsiboukli, 2012

viii Rogers, 1999
} 
resistance of older persons themselves to forms of education is also an obstacle to implementing such programmes. This resistance to return to the learning process lies in the fact that they see themselves as too old, they lack motivation and self-confidence, they are worried about being compared to younger adults or that any limitations in their educational background will be exposed (WHO, 2015).

There are also practical problems, such as the cost of classes, lack of time, insufficient information on available programmes, lack of knowledge about or ability to access the programme locations. Moreover, the stereotype that older people have weaker memories has been disproved by relevant studies and transposed into an advantage, as they have more accumulated information and better critical judgment due to life experiences (ibid.).

Nevertheless, studies have shown that when learning programmes are offered through cultural facilities in cooperation with local government, such as a museum, and are supported by a cultural dimension, then they are more acceptable to the third age. Such specially prepared programmes focus on holistically stimulating their interest. Personal expression through culture and the breadth of teaching methods this requires (full sensory participation) creates a multidimensional learning environment that evolves into something polysemous and versatile, while also focusing on the needs of the specific age range. Thus, older people develop better functionality and assimilation indicators while meeting the criteria for better quality of life (Varbanova, 2011).

\section{Material and Methods}

\subsection{The survey at the Syros KAPI}

According to the Hellenic Statistical Authority (ELSTAT-2011 census), the percentage of older people living in Syros makes up $20 \%$ of the total permanent population. This means that the local community under study has a large number of older persons confined to a small, insular environment, without a great many options for travel due to ferry schedules and the state of their health that me result from their advancing age. In such a population setting, the adapted structure of learning programmes for the third age acquires greater value. The fact that the third-age population of the South Aegean Region is $20 \%$ of the total population ${ }^{\text {ix }}$ is predicative that the study with a sample in Syros could serve as a pilot study for further implementation of third-age learning programmes.

The incentive for this study was the lack of learning structures for the third age in Syros at a time when both the academic community and the directives from the European Union have demonstrated the benefits of such programmes, as well as that such programmes are a practicable and sustainable solution. The question is thus raised of why, on an island such as Syros, with a sizeable older population, with a long presence of an active KAPI and a good cultural and social level, no lifelong learning services have

\footnotetext{
ix ELSTAT, 2011
} 
been created for the third age. The research questions included led to the study of this issue:

1) To what extent do the members of the Syros KAPI wish to take part in lifelong learning programmes and what factors influence such a decision (e.g. social/family environment, educational background, family status, mental and psychological functions, etc.)?

2) What are the motivations of the older members of the KAPI and potential expectations regarding their participation in such a form of learning? Are they linked to the intellectual and cultural setting of the small insular society in which they live?

3) What are the objects of knowledge that older persons of the Syros KAPI would like to engage with during the group process? Would special conditions be a prerequisite and what would they be?

To ensure a more thorough description and analysis of findings, the methodology involved a qualitative survey, though a questionnaire distributed to members of KAPI centres in Syros, as it primarily involves a social issue; therefore, there is a need for an overall, in-depth understanding of the data. Nevertheless, some quantitative measurements were also taken that are in line with the statistical review of trends to document the current situation more thoroughly.

It is worth noting that the interaction with older people entails special requirements, mainly the mandatory presence of the researcher to provide assistance with completing the questionnaires and is worth describing. Because the survey was onsite and verbal and because the respondents did not want to read the questions and write the answers, part of the precision of the responses was lost, and it was considered appropriate that the questionnaire not be distributed to members but filled out in the researcher's presence; each member was alone, rather than in a group of people, where, because of their social relationship, their views may not have been authentic. In this way, there was an opportunity to clarify any queries regarding the phrasing of the questions and any superficial and simplistic answers were avoided. In addition, to ensure that the findings would be as comprehensive as possible, the researcher discreetly prevented some KAPI members from participating, either because they belong to the fourth age (over the age of 80) or because they had obvious mental health issues. Lastly, some individual responses were recorded as notes immediately after the interview.

The KAPI centres were selected because the older people have consciously chosen to be in a space of networking and socialisation and is therefore considered to be fertile ground for implementing learning programmes. In addition, KAPI members are familiar with conditions for exchanging views, a sense of belonging to a group and intention to counteract the problems of ageing through the KAPI institution.

The data were collected in March 2019 on the premises of the local KAPI centres in Syros. The presence of the researcher while the questionnaires were being completed by KAPI members was essential, so that, firstly, sufficient data could be collected in a 
short time and, secondly, to assist the older people. The meetings were held in the familiar KAPI premises, where the questions were read out and the answers given verbally, for the convenience of the older participants. In each case, the respondents were given an opportunity to comment further on their answers, and these comments are included in the study results. This helped them to freely and more thoroughly express their beliefs, experiences and feelings. The purpose was to record the social reality, as the older respondents ${ }^{\mathrm{x}}$ experience it, as accurately as possible during the sessions, which was deemed particularly important for preciseness of the responses. It is also believed that the tight-knit social environment of the small island community and the good reputation of the researcher as an active member, as well as the researcher's experience in the area of adult education, helped to draw out answers that were free of worry about exposure, so as to protect the integrity of the survey.

\section{Results and Discussion}

The respondents comprised 9 men and 21 women, aged 55 to 75 . The majority which was more available to respond were women who are mainly homemakers, though many of them had worked in their youth at local factories but were unable to work long enough to qualify for pensions. The respondent profile showed that just $10 \%$ were relatively familiar with the internet and technology.

According to the survey conclusions, most of the older people-members of the Syros KAPI had not had an opportunity in the past to attend a lifelong learning programme $(86 \%)$. Some had taken part in sporadic workshops held especially for the third age and some in general training courses for adults. In addition, $62 \%$ had taken part in individual educational activities held by the KAPI as part of its institutional mandate. Moreover, quite a few were aware that there are learning programmes around the world especially for the third age, which they rated at $6 / 10$ or greater. Therefore, this emerged as a mature audience, prepared to revise its positions on active ageing and to agree to take part in learning programmes. It is also noted that the survey served as an opportunity to inform them of such services, which they viewed with restrained interest. With regard to the intent of these older persons to attend lifelong learning programmes and the factors that would influence such a decision, the responses were generally positive $(45 \%)$, though some trepidation was expressed. Specifically, most (75\%) responded with curiosity to the prospect of creating educational services for the third age in Syros and quite a few (22\%) with enthusiasm and satisfaction (15\%). Half of them would take part in courses, while the decision of a sufficient proportion would depend on the knowledge object. This finding is important in planning an educational programme in order to adapt it to the preferences of the older people living in the insular environment of Syros.

$\times$ Iosifidis, 2003 
The question of whether they would participate in an educational programme sought to explore the intent of KAPI members, and was found to be sufficiently positive, at $55 \%$. The remaining responses were delegated to negative responses $(24 \%)$ and to the specific condition "depending on the object" $(21 \%)$. The negative responses included hesitation due to age (36\%) and equally a shortage of time, citing family obligations such as caring for grandchildren and caring for partners or adult children living with them at home. This is a serious inhibitor to intentions, unique to the Greek family which involves a broad social system and is potentially difficult to overcome; there is an entrenched belief that people in the third age should do nothing beyond their prescribed roles. In addition, a considerable percentage cited problems of transport $(21 \%)$, or health problems $(36 \%)$.

Of those who would participate in a learning programme, 55\% would do so to overcome loneliness and associated feelings; $21 \%$ in part because their social environment is limited (death of people close to them) or because the existing social and family environment is active and busy with work or personal matters. About $17 \%$ noted as a related reason the need to make use of the ample free time that becomes available after retirement. Another $17 \%$ noted the inclination of older people not to be overlooked because of their outdated knowledge and skills, compared to the progress being made in society. On the contrary, they wish to keep up with the demands of the times, perhaps not to the fullest, but certainly by taking steps to improve their position in their era. The same rate was noted in the need to make up for the lost time of their youth, when due to historical or social circumstances, they had not had the opportunity to pursue their studies. They understand that the dream they may have had when younger will not be fulfilled completely but attending some course would be a consolation. Moreover, 14\%, which is not a large proportion but sufficient to be worthy of note in the survey, said they would be persuaded by other members of the KAPI, usually from amongst their friends or as a show of competitiveness. ${ }^{x i}$ They believe their participation in learning structures would be the ideal starting point for exercising their brains, in an act of resistance against illnesses such as dementia and depression. Another $14 \%$ was noted for older people complaining that learning programmes were mostly created for younger people. The presence of an average rate for such a declaration makes clear the need to take account of the need for education in the third age of an active society, as a social reward for their efforts when they were of an active age (17\%), but also to fill up their free time. Their desire to continue to be active members, accepted by society, and to be treated equally or proportionately as those of a productive age (17\%) was also expressed.

In fact, a strong majority would use its acquired skills to benefit the island, with a response rate of $96 \%$. The proposals that were heard were quite imaginative: Some mentioned administrative support for the social pharmacy; others thought they could help organise individual events and festivals for non-profit organisations by taking on

\footnotetext{
xi The expression of one woman was typical when she said she would take part "to impress another member", which might sound like a funny reason, but it has been shown to be motivational, perhaps in an advertising campaign, which is why it is mentioned in the survey results.
} 
secondary roles as volunteers; others wanted to become active in guiding visitors at museums and the Apollo Theatre; some believe they could help young children with their lessons, amongst others. On an island with extensive cultural activity striving for tourism development, they wish to acquire skills to keep up with the times and the demands of local growth. This is demonstrated by their responses regarding whether they intend to channel their new knowledge towards their social environment. It becomes obvious that older people need to be independent and socially functional, and this translates into a need to change into active, useful citizens of the local community. Some of their comments follow: "I could participate in the festivals that take place on the island," "They needed someone to keep the files at the social pharmacy, but I didn't know how,", etc.

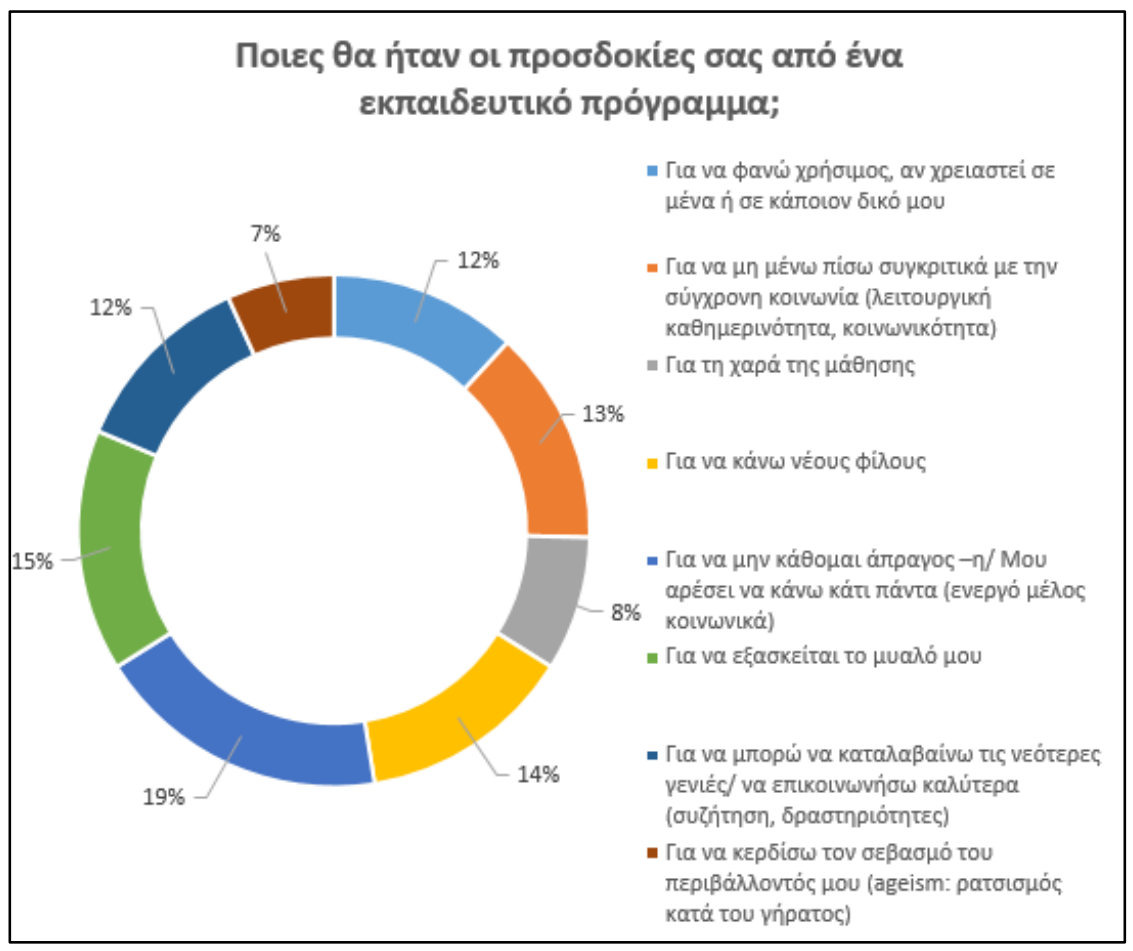

Figure 1: Expectations of older people with regard to training programmes

As for the courses in the training programme, the KAPI members could choose from amongst computers (21\%) and internet (16\%) $)^{\mathrm{xi}}$, traditional occupational arts (3\%), foreign languages and health topics (14\%), technical skills $(2 \%)$, courses on economics (21\%), popular culture (storytelling, folk dancing, etc.) (9\%), crafts and cookery (14\%), performing arts, history and literature (3\%), local history and customs (3\%), health issues related to ageing, rights of European citizens (9\%), creative writing (3\%). Three respondents said that yoga was missing from the list of courses, while creative writing and the rights of European citizens had zero response. As to the frequency of attending

\footnotetext{
xii One isolated course was in progress while the survey was being conducted which was well received by KAPI members. This may have influenced their choices.
} 
the courses, the older persons tended to prefer a more relaxed schedule of studies, with $66 \%$ preferring courses on a weekly basis.

The make-up of the learner groups seems to interest the older persons, but they do not set stringent criteria. Half of them said they do not care how many people would be in the class, while $35 \%$ thought that 10 people would be enough for a good class. A small rate $(5 \%)$ would like to take part in smaller groups of 5 persons, while very few (4\%) preferred crowded classrooms. Regarding the other characteristics of the group, there was an evident preference for mixed sections made up of people close in age and similar educational level, in other words for homogeneity in the learner groups. However, there was also a portion who would like to know the people in the same group socially (14\%), and those who would not care about the make-up of the group at all (11\%). As for the manner in which they believe they would learn better, the members of the Syros KAPI prefer interaction and teamwork as methods: discussion received $36 \%$ of responses, and group projects, 20\%. The remaining choices (presentation by a teacher, practical exercises, educational visits, guided personal research, contact with experts in the field) had smaller values, perhaps because the respondents are not very familiar with the educational field, while the choice of learning through educational games got no response. Additionally, difficulties in learning they identified are mainly their ability to understand and their reliability, which recurs in the survey and reaffirms the less than high priority given to their participation in educational programmes, apparently in comparison to their social and family obligations, as indicated by a previous question.

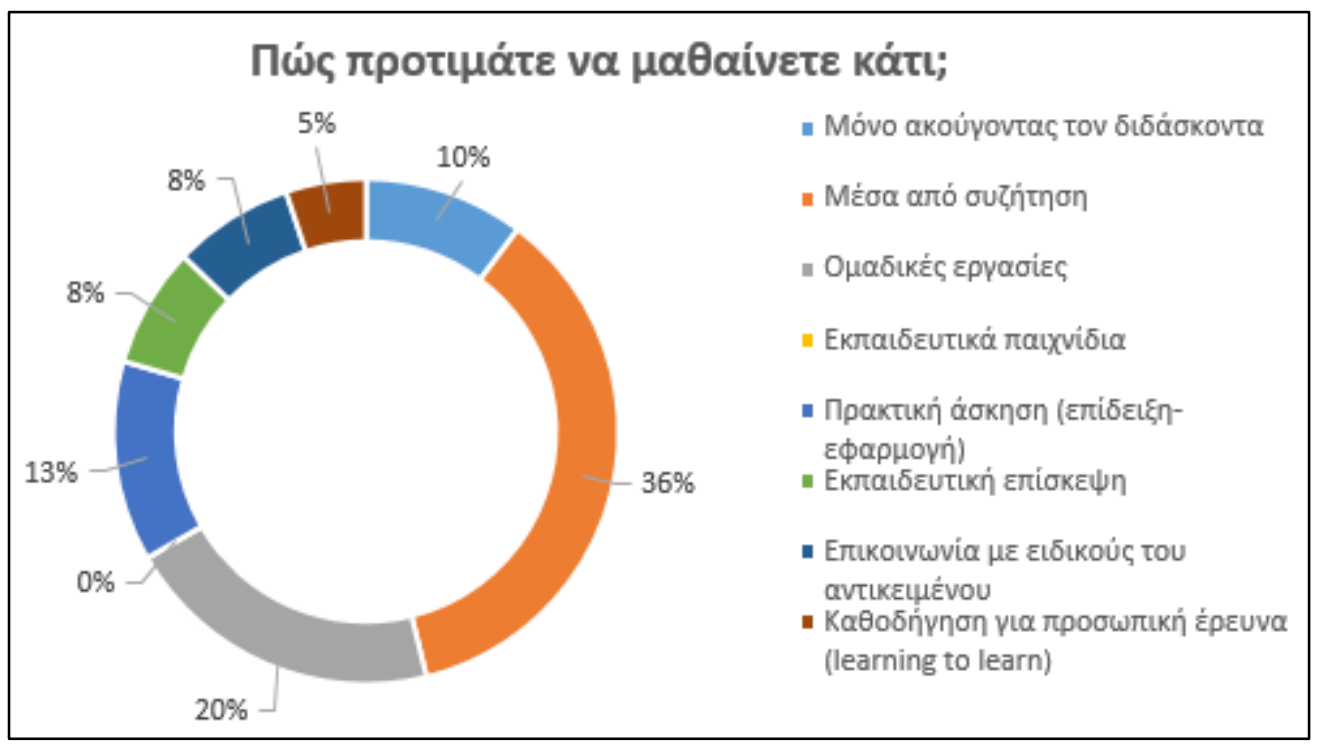

Figure 2: Preferred learning methods

The preference of more relaxed participation is reaffirmed yet again by the characteristics that older people would choose for the ideal instructor: Primarily, to speak in a way that is understood (29\%), to be pleasant $(18 \%)$ and not to assign homework $(16 \%)$. They also did not ascribe any weight to the instructor's inclination to provide 
encouragement nor any requirement related to strictness - which is in line with the more conservative nature of the older generation. This could lead to conflicting conclusions between the fact they already feel safe with the undertaking or, on the other hand, they are not interested enough in it to desire the instructor's complete dedication.

As regards the location for the courses, the findings indicated that the KAPI would be the ideal place for holding learning programmes, with a strong percentage of $67 \%$. A noteworthy share of $29 \%$ would like them to be held outside the KAPI facilities, while $4 \%$ were not concerned about the location. Those selecting the KAPI cited practical reasons, i.e. combining classes with other KAPI activities (79\%), whilst $21 \%$ based their choice on their familiarity with the space. Those who would prefer a different location for classes (78\% of them) believe that such courses would be an excellent opportunity to change venues and keep the KAPI separate as a place for meeting socially with people their age. It is also noteworthy that the $22 \%$ who expressed dislike for other members may have seen the courses as an opportunity to explore new meeting places.

\section{Recommendations}

As correctly stated in the WHO report, xiii public policy must take into account that for some older persons, extending the learning process beyond formal education signals a very significant phase in their life. As such, the curriculum and teaching approach of lifelong learning programmes should be adapted so that older persons can participate successfully. Moreover, using a variety of means, courses and programmes, such as open universities, should be designed for third-age persons that foster group learning and treat them as partners in activities or internet programmes so that individuals can participate from any place. It is also typical that the objects of knowledge selected by the survey participants are related to cultural or technological activities. Having acquired these skills, they could then make use of them as volunteers for local events in a variety of positions. In any case, this type of learning makes them a more mature audience for cultural actions in their place of residence.

As to the KAPI institution, this could be enriched with training programmes for the third age and be transformed into a type of educational organisation for the third age, along the lines of the Third Age University model, as part of its reorientation to the new needs of the times. Besides, since the 1970s in the USA, educational programmes for the third age have developed as extension of community adult education programmes, when existing offerings were adapted to the needs of older persons and which are now flourishing. ${ }^{x i v}$ For this reason, local government, to which oversight of lifelong learning services has been transferred, will have to assist, and initiatives will have to come from the central government. The development of learning programmes for older persons and

\footnotetext{
xiii “World Report on Ageing and Health", 2015

xiv Peterson, 1990
} 
groups of vulnerable older persons can aim at making use of their skills to the benefit of themselves and of the local community.

As far as Syros is concerned, it is proposed that a process to create educational structures for the third age should begin through the KAPI institution on a pilot basis. In fact, it would be a good idea to begin with programmes on digital literacy for three reasons: Firstly, because it the first choice on the questionnaire, and therefore fits with the most popular interests of older people; secondly, because a knowledge of computers and the internet would facilitate learning of subsequently chosen learning objects; and finally because this knowledge can be put to use immediately, once volunteer positions are created in the Municipality's cultural department. Given that such an undertaking has every chance at succeeding, it would create a store of training programmes that can be periodically enriched. Its success will draw the attention of other older people who can also participate in this object and later in others.

Finally, as regards further research, it is essential to further explore the expectations and motivations of older persons in view of lifelong learning. This could be done either as a research project within the relevant university communities, or as a research phase within competent bodies under private and public law, as part of the strategic planning of training programmes.

\section{Conclusion}

In taking a holistic view, the findings of this survey acquire significance because it is the first time a survey has been conducted on the educational and cultural needs and the benefits of informal learning programmes for the third age. Other studies have already highlighted their importance, but the insularity and unique characteristics of life in Syros could help orient the design of such educational programmes towards a more customised profile. It would not be possible to apply the same business plan to a small population, as compared to urban centres, that is largely concentrated on a medium-sized island as one might to a crowded local community. Based on the premise that a central mechanism needs to be individualised and adapted to the special needs of a place, this study could be useful in this planning to ensure the success of the educational programmes.

\section{Conflict of Interest Statement}

The authors declare no conflicts of interests.

\section{About the Authors}

Christianna Papitsi is a PhD Candidate in the Department of Industrial Design \& Production Engineering at the University of West Attica. She holds an MSc in both X from the University of $X$ and in $X$ from the University of $X$. She has studied $X$ and teaches Information Technology at a Greek public school as an hourly instructor, and has also worked as a trainer with adult learners at public vocational training institutes. Her 
research interests include cultural communication and lifelong learning as a modern cultural necessity.

Dr. Theodoros Ganetsos is a Professor at the School of Engineering-Industrial Design \& Production Engineering at the University of West Attica, where he teaches NonDestructive Techniques and Digitisation in Cultural Heritage Using New Technologies. He has done extensive research and has been widely published.

Dr. Michail Papoutsidakis is a Professor at the School of Engineering-Industrial Design \& Production Engineering at the University of West Attica. His doctoral dissertation was on modern methods for automatic control with applications in motion systems, while his post-doctoral research is on developing motion design algorithms for an autonomous mechatronic space surveillance vehicle and wireless image transfer with a combined use of micro-cameras.

Dr. Christos Drosos is a Lecturer in the Industrial Design \& Production Engineering Department at the University of West Attica. He holds a BSc in Automation and Control System Engineering, an MSc in Informatics and a PhD in Informatics from the University of Piraeus. He has also conducted post-doctoral research on Informatics at the University of Thessaly.

Dr. Dimitris Tseles is a Professor in the Industrial Design \& Production Engineering Department at the University of West Attica. He is the founder and a member of the Research Laboratory of Electronic Automation, Telematics and Cyber-Physical Systems. He holds a BSc in Physics, and an MSc and PhD in Electronic Control. He is the President of the eRA International Scientific Conferences, a member of various institutes and associations and director of many research projects in various fields.

\section{References}

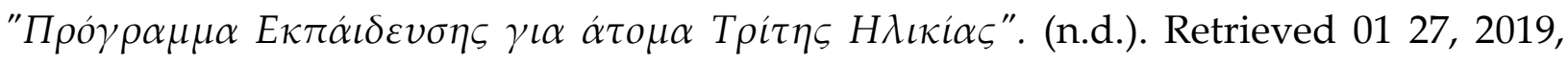

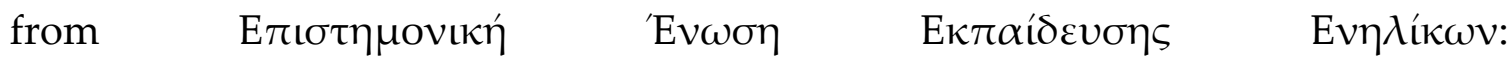
http://www.adulteduc.gr/2015-02-07-11-22-20/2015-02-07-11-25-9/38-2015-03-0910-19-6

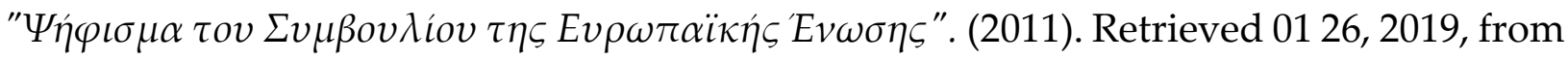

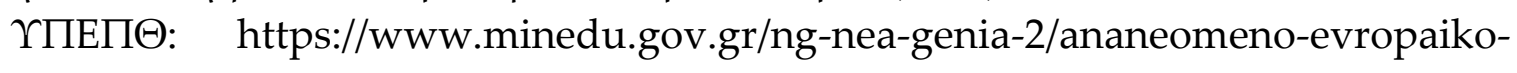
thematologio-gia-tin-ekpaidefsi-enilikon

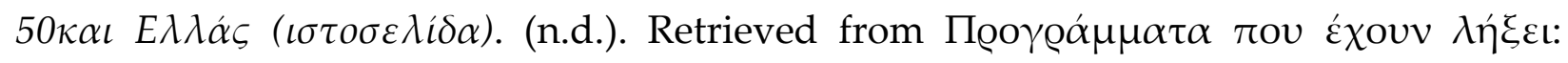

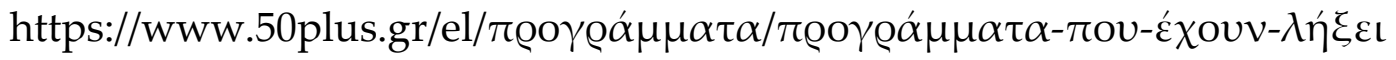

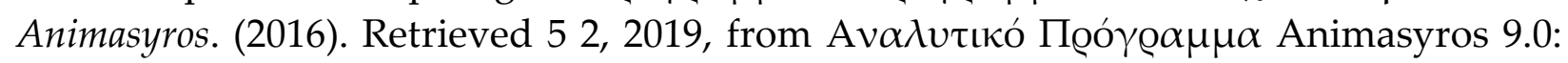

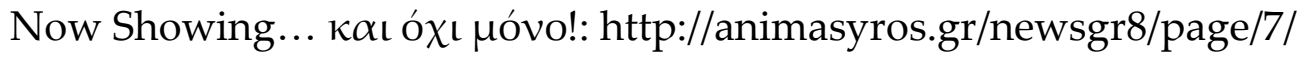

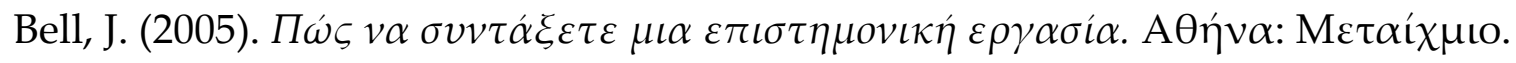


Coombs, P. (1968). The World Educational Crisis: A Systems Analysis. New York: Oxford University Press. Retrieved from https://eclass.upatras.gr/modules/document/file.php/PN1453/Coombs.pdf

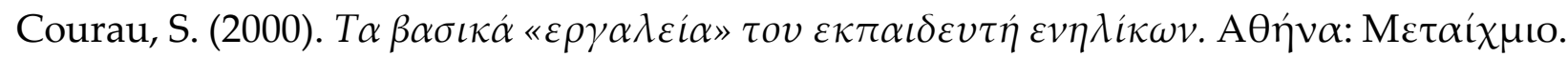

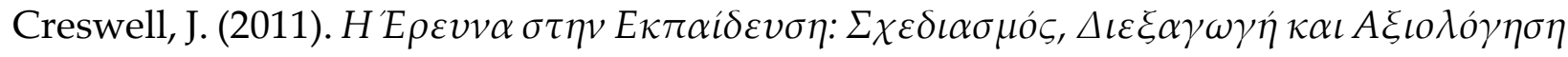

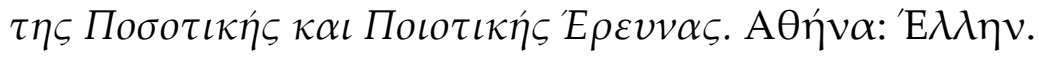

De Donder, L., Brosens, D., De Witte, N., Buffel, T., Dury, S., Smercoren, A.-S., \& Verté, D. (2014). Lifelong Learning in Old Age: Results from the Belgian Ageing Studies

- 5th World COnference on Educational Sciences. Procedia Social and Behavioral Sciences (116), pp. 513-517. Retrieved from https://www.sciencedirect.com/science/article/pii/S1877042814002511

Differences And Similarities Between The French And British Versions Of U3A. (n.d.). Retrieved 3 1, 2019, from The University of the Third Age: http://www.aiu3a.com/differences-and-similarities/

EPALE. (n.d.). Electronic Platform for Adult Learning in Europe. Retrieved from European Commission: https://ec.europa.eu/epale/en/nss

EU policy in the field of adult learning. (n.d.). Retrieved 01 26, 2019, from European Commission - Education and Training: https://ec.europa.eu/education/policies/eu-policy-in-the-field-of-adultlearning_en

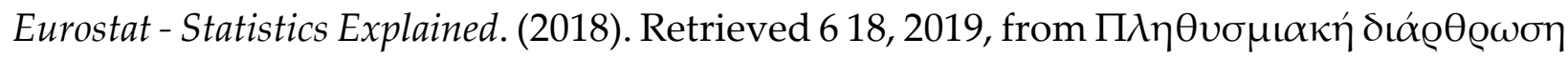

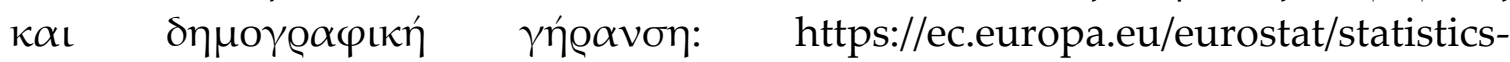
explained/index.php?title=Population_structure_and_ageing/el\&oldid=409484

EUROSTAT. (2018, 11 8). Adult learning_YB2018. Retrieved 01 26, 2019, from EUROSTAT: https://ec.europa.eu/eurostat/statistics-

explained/index.php?title=File:Adult_learning_YB2018.xlsx\&oldid $=411840$

Findsen, B. (2005). Learning later. USA: Krieger Publishing.

Hansen, A., \& Zipsane, H. (2013). Older people as a developing market for cultural heritage sites. In H. Zipsane, \& M. Sani, Creativity, lifelong learning and the ageing population (pp. 35-43). Fornvårdare.

Healthy Ageing and the Sustainable Development Goals. (n.d.). Retrieved 3 2, 2019, from World Health Organization: https://www.who.int/ageing/sdgs/en/

Jones, K. (1984, 3). Psychological Problems in the Elderly. Canadian Family Physician/Médecin de Famille Canadien, 30, pp. 591-593. Retrieved from https://www.ncbi.nlm.nih.gov/pmc/articles/PMC2154185/

Klercq, J. (2009). Learning in Later Life. European Approaches ans Issues. Retrieved 01 26, 2019, from Learn for Life. Dutch Platform for International Adult Learning: http://platformlearnforlife.nl/documents/JumboKlercqLearninginLaterLife.pdf

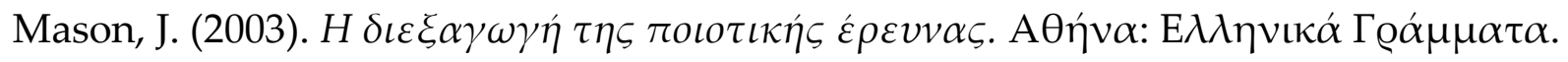


MATURE. (2013, June 13). MATURE Research Report. MATURE Project. Retrieved 1 24, 2019, from matureproject.eu: http://matureproject.eu/wpcontent/uploads/2013/01/MATURE-Research_upload_versionC_100613.pdf

OECD. (2001). Lifelong Learning for All. Policy Directions - Chapter 1. OECD. Retrieved 619, 2019, from http://www.oecd.org/officialdocuments/publicdisplaydocumentpdf/?cote=DEEL SA/ED/CERI/CD(2000)12/PART1/REV2\&docLanguage=En

Participation in Vardakeios School in the European Erasmus+ project "Digi-S Teaching Basic Digital Competences for Seniors “. (2018, 10 05). Retrieved 1 26, 2019, from ec.europa.eu: https://ec.europa.eu/epale/en/content/participation-vardakeiosschool-european-erasmus-project-digi-s-teaching-basic-digital

Peterson, D. (1990). A History of the Education of Older Learners. In R. Sherron, \& B. Lumsden, Introduction to Educational Geronotology (pp. 4-19). USA: Hemisphere Publishing Corporation.

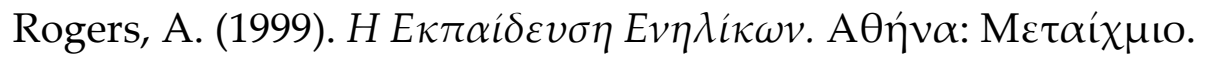

Rowe, J., \& Kahn, R. (1997, 8). Successful Aging. (T. G. America, Ed.) The Gerontologist, 37(4), pp. 433-440. Retrieved 2 15, 2019, from https://academic.oup.com/gerontologist/article/37/4/433/611033

(2017). The 2018 Ageing Report. Underlying Assumptions \& Projection Methodologies. European Commission. Retrieved 1 24, 2019, from https://ec.europa.eu/info/sites/info/files/economy-finance/ip065_en.pdf \& https://ec.europa.eu/info/publications/economy-finance/2018-ageing-reportunderlying-assumptions-and-projection-methodologies_en

The BeLL Project. (2014). Benefits of Lifelong Learning in Europe (BeLL): Main Results of the BeLL-Project. BeLL. Retrieved 126, 2019, from http://www.bell-project.eu/cms/wpcontent/uploads/2014/06/BeLL-Research-Report.pdf

The Impact Of Learning At Third Age University To Health. (n.d.). Retrieved 3 1, 2019, from The University of Third Age: http://www.aiu3a.com/impact-to-health/

The Origin and Purpose of The University of The Third Age. (n.d.). Retrieved 3 1, 2019, from aiu3a: http://www.aiu3a.com/origin-and-purpose/

Universités du troisième âge. Qu'est ce que c'est ? (n.d.). Retrieved 31, 2019, from Le Figaro. Santé: $\quad$ http://sante.lefigaro.fr/social/personnes-agees/universites-troisiemeage/quest-ce-que-cest

Varbanova, L. (2011). Cultural participation in education and lifelong learning: a catalyst for personal advancement, community development, social change and economic growth. European Commission. Retrieved from http://www.houseforculture.eu/upload/Docs\%20ACP/Accesstoculturepolicysum maryAugust312012updatedFormated1.pdf

Wellington, J. (2000). Educational Research. Contemporary Issues and Practical Approaches. London: Continuum. 
WHO. (2011). Global Health and Aging. World Health Organization. Retrieved from https://www.who.int/ageing/publications/global_health.pdf

WHO. (2015). World Report on Ageing and Health. World Health Organization.

Why adult education? (2019). Retrieved 1 25, 2019, from European Association for the Education of Adults (EAEA): https://eaea.org/why-adult-education-2/

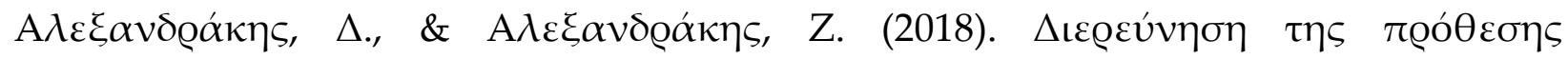

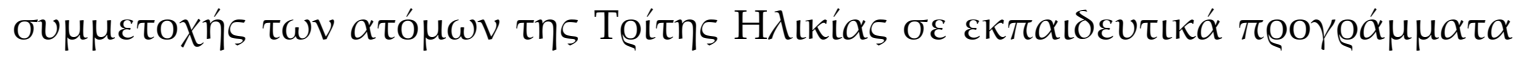

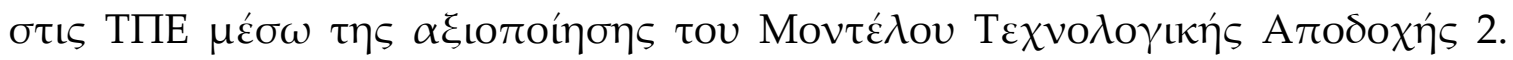

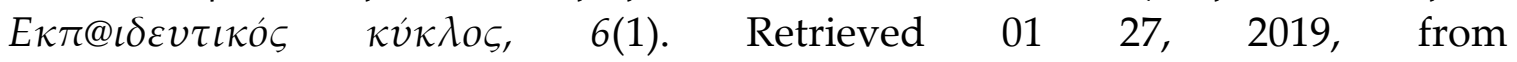
http://journal.educircle.gr/images/teuxos/2018/teuxos1/teyxos_6_1_5.pdf

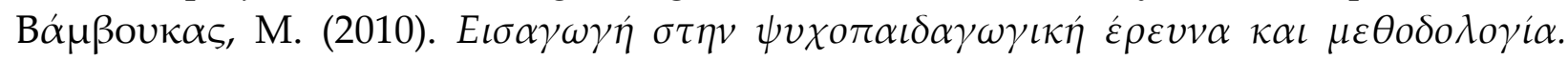

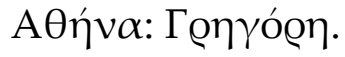

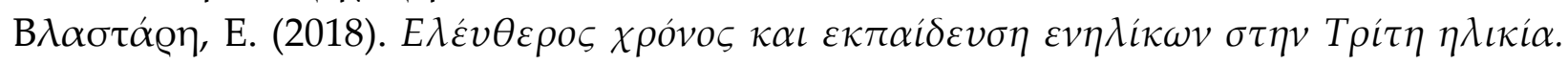

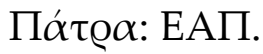

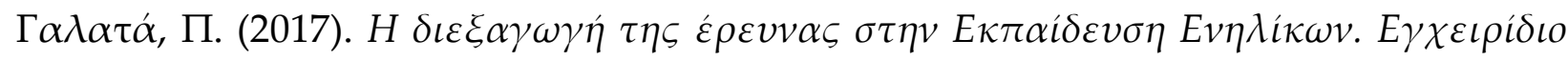

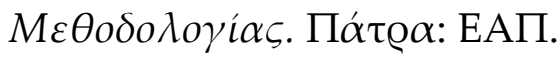

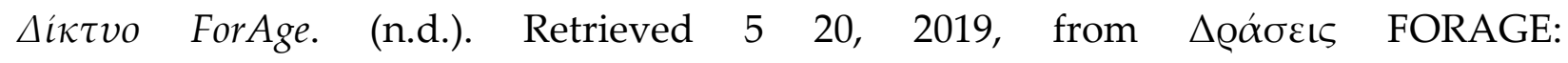
http://foragenetwork.eu/gr/page/55-forage/

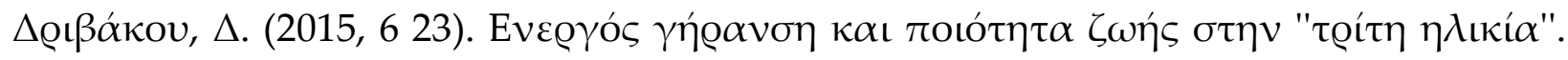
psychology now. Retrieved 328,2019 , from https://www.psychologynow.gr/arthrapsyxologias/koinonia/koinoniki-psyxologia/518-energos-giransi-ke-piotita-zoisstin-triti-ilikia-tis-despinas-dribaku.html

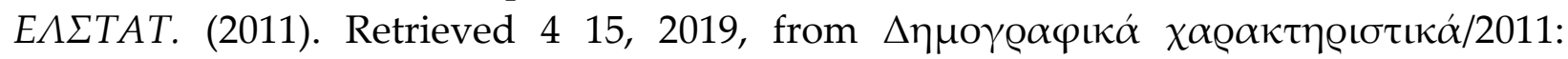
http://www.statistics.gr/el/statistics/-/publication/SAM03/-

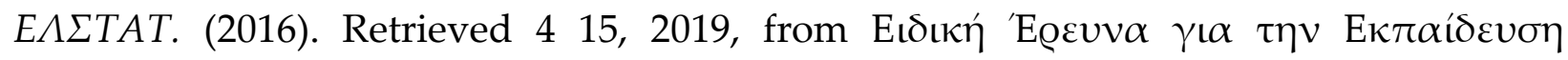

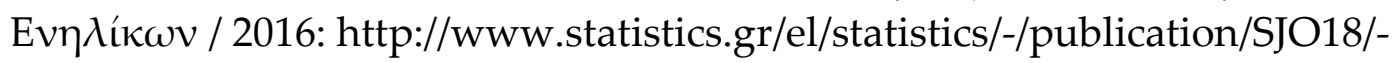

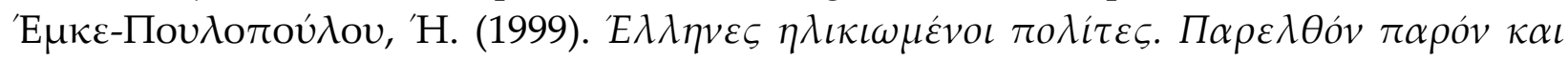

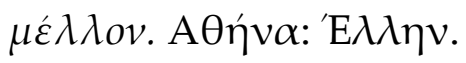

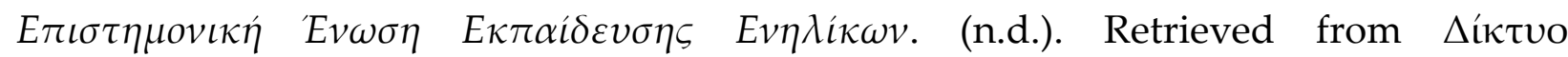

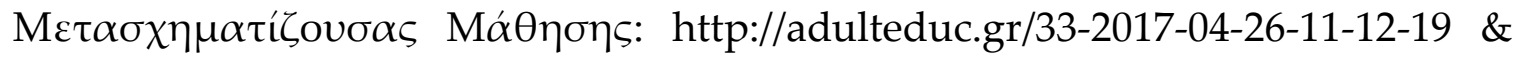
http://www.adulteduc.gr/2015-02-07-11-22-20/2015-02-07-11-25-9

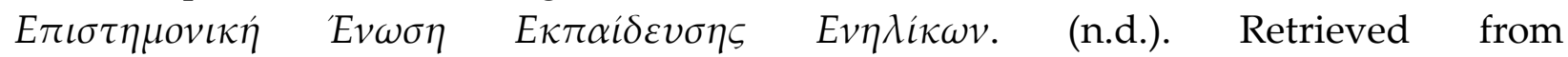
http://www.adulteduc.gr/

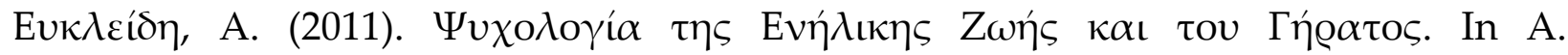

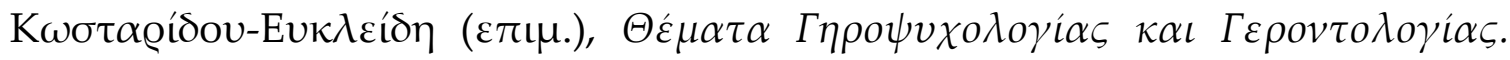

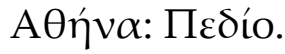

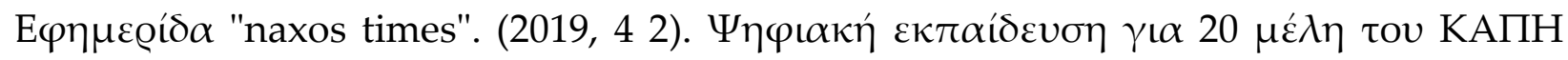

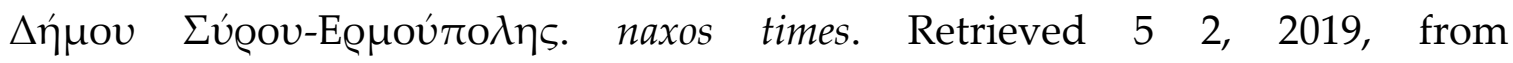
https://www.naxostimes.gr/koinonia/34988/psifiaki-ekpaidefsi-gia-20-meli-toukapi-dimou-syrou-ermoypolis/ 


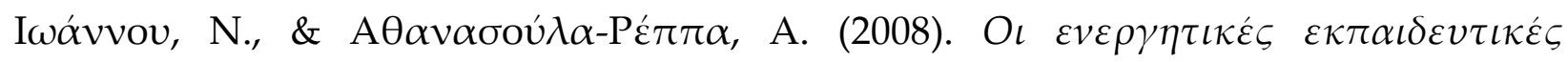

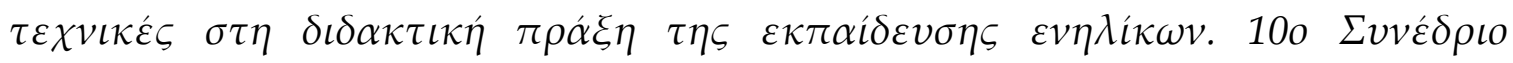

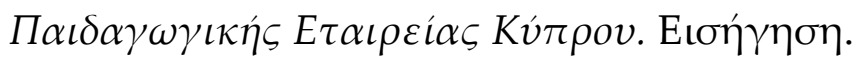

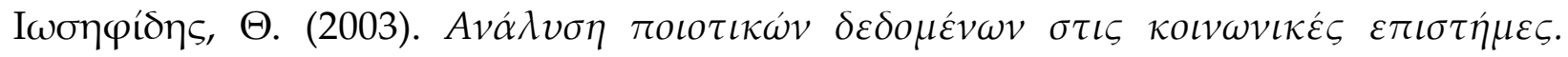

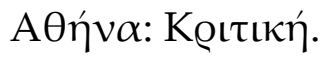

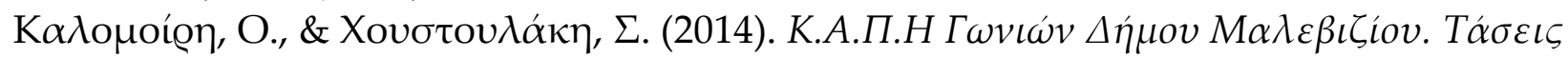

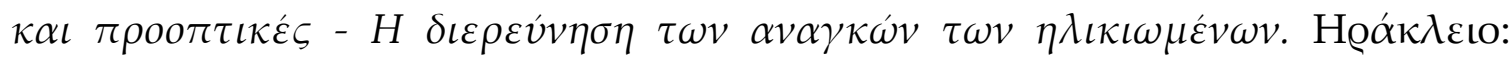

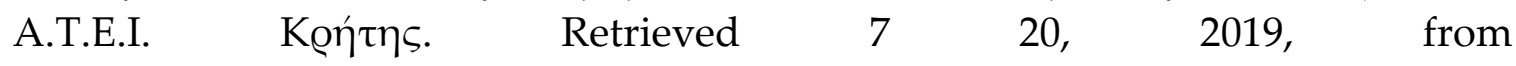
https://apothesis.lib.teicrete.gr/bitstream/handle/11713/1097/KalomoiriOurania_ ChoustoulakiStyliani2014.pdf?sequence $=1 \&$ isAllowed $=\mathrm{y}$

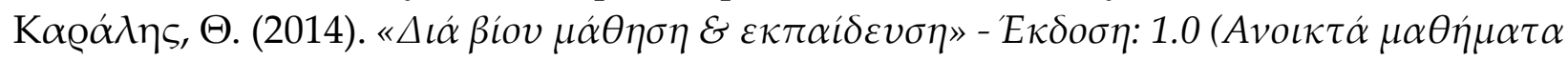

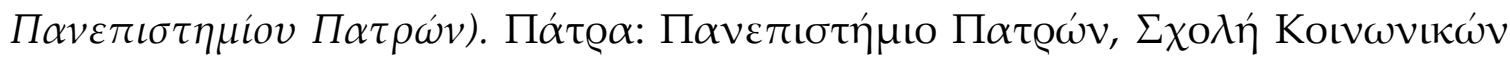

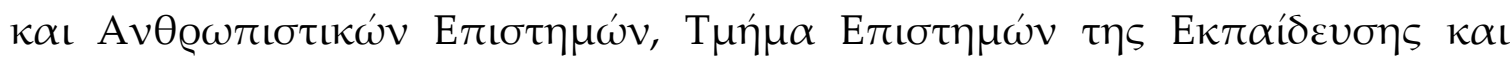

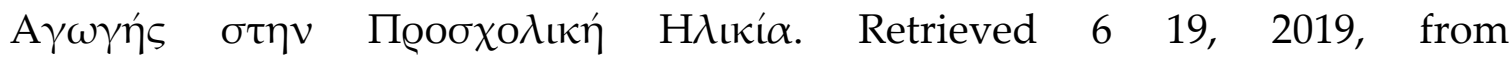

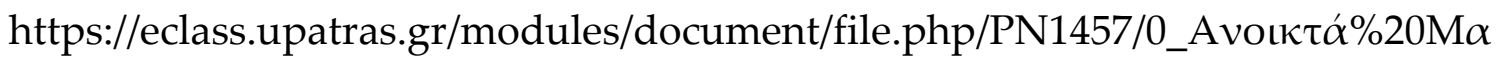

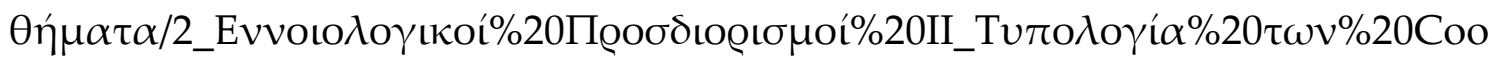
mbs\%20\%26\%20Ahmed.pdf

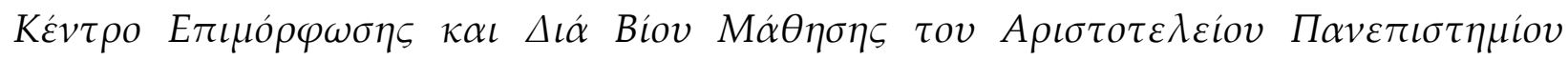

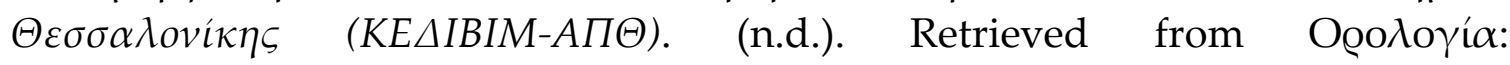
http://www.diaviou.auth.gr/definitions

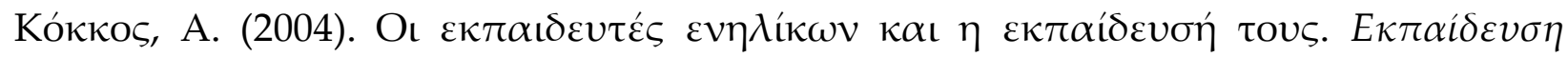
Ev $\eta \lambda \iota \kappa \omega v(1)$, pp. 12-23.

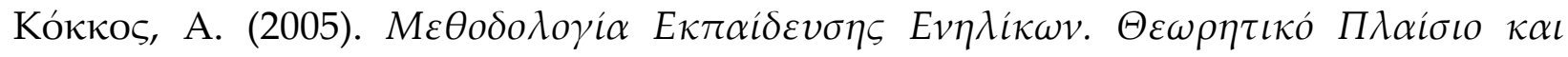

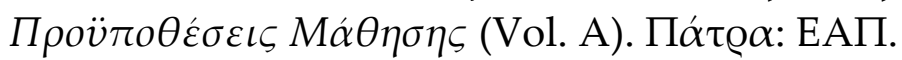

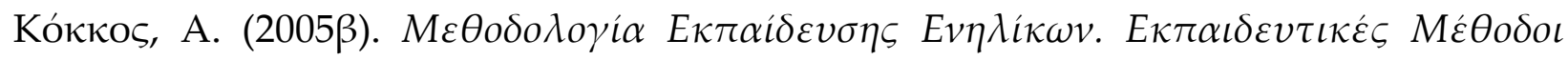

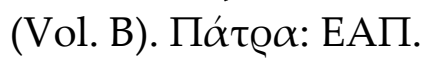

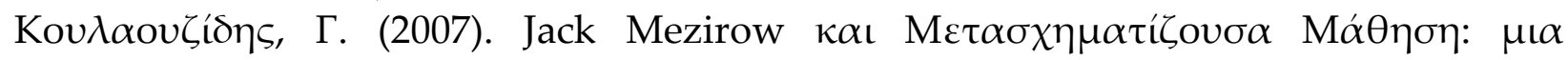

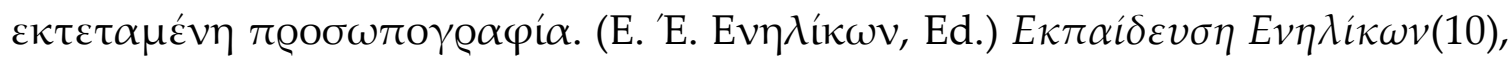
pp. 36-39. Retrieved 6 15, 2019, from http://www.adulteduc.gr/images/10_jack_mezirow.pdf

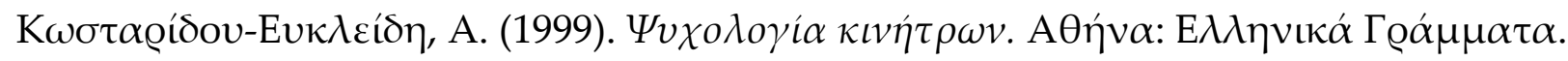

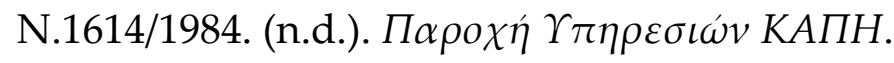

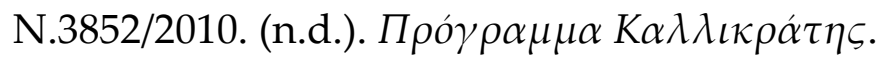

N. $\Delta .162 / 73$. (n.d.). $\Phi E K A^{\prime} 227$.

П. $\Delta .329 / 89$. (n.d.).

П. $\Delta .631 / 74$. (n.d.). $\Phi E K A^{\prime} 271$.

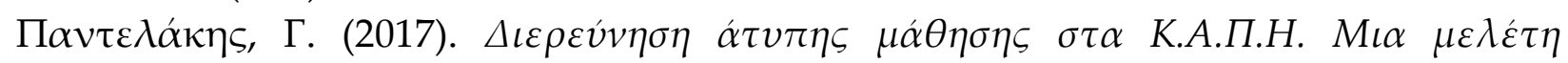

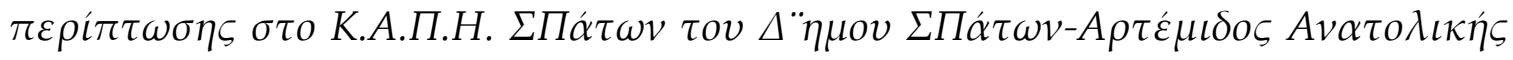

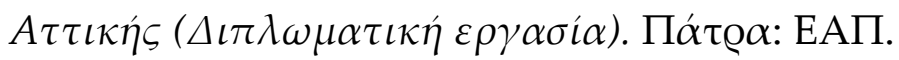

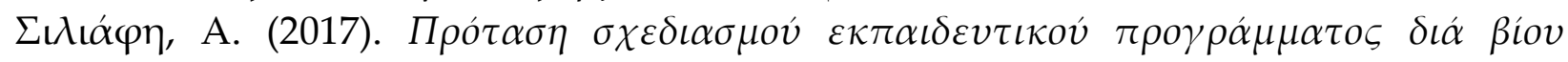

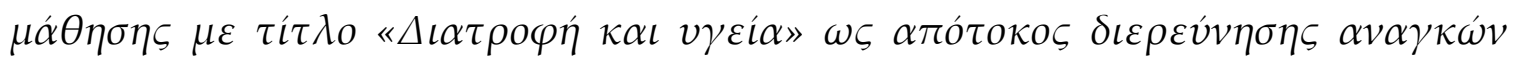




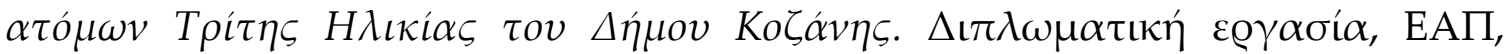

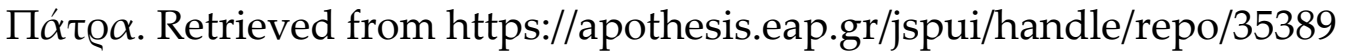

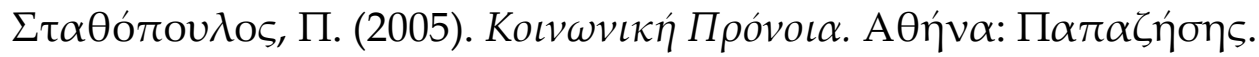

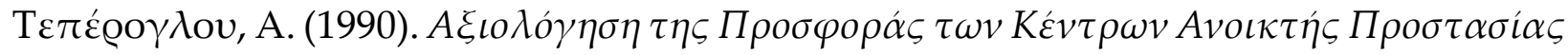
$H \lambda \iota \kappa \iota \omega \mu \dot{v} v \omega v$. A $\theta \dot{v} v \alpha:$ EKKE.

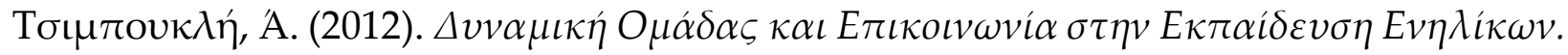
A $\theta \eta \dot{v} \alpha:$ INE/Г $\Sigma E E$.

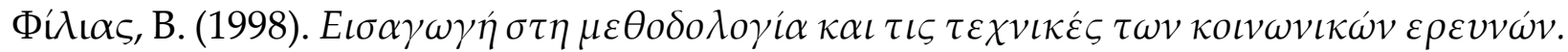

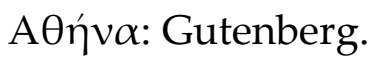
makes clear that the materials are being reused under permission of a Creative Commons License. Views, opinions and conclusions expressed in this research article are views, opinions and conclusions of the author(s). Open Access Publishing Group and European Journal of Education Studies shall not be responsible or answerable for any loss, damage or liability caused in relation to/arising out of conflicts of interest, copyright violations and inappropriate or inaccurate use of any kind content related or integrated into the research work. All the published works are meeting the Open Access Publishing requirements and can be freely accessed, shared, modified, distributed and used in educational, commercial and non-commercial purposes under a Creative Commons Attribution 4.0 International License (CC BY 4.0). 